\title{
Intramural haematoma and dissection following idiopathic VT ablation
}

\author{
Swee-Chong Seow $\cdot$ Wee-Tiong Yeo • \\ Winn Maung Maung Aye
}

Received: 13 October 2012 / Accepted: 17 January 2013 /Published online: 14 April 2013

(C) Springer Science+Business Media New York 2013

\section{Introduction}

A 48-year-old male underwent ablation for posterior fascicular ventricular tachycardia (VT).

\section{Methods and results}

Ablation was performed in sinus rhythm using a thermocouple catheter at the exit site [1]. A line of lesions was also created from the mid-septum to the inferior border of the heart at the intersection of the middle and distal third of the septum [2]. Radiofrequency (RF) energy was delivered at $40 \mathrm{~W}$ and for $30 \mathrm{~s}$ at each spot. Following ablation, the patient became hypotensive. Echocardiogram revealed pericardial effusion with tamponade.

During exploratory surgery, a large haematoma was noted on the anterolateral wall of the left ventricle (LV) with epicardial disruption (Fig. 1). After haemostasis was secured, the patient was transferred to intensive care. Three hours later, he collapsed and eventually perished.

Post-mortem examination showed a ruptured septal branch of the left anterior descending artery resulting from $\mathrm{RF}$ ablation, leading to bleeding into the myocardium. This intramural haematoma had dissected through to the epicardium and the anterolateral LV.

\section{Discussion}

This is a rare complication of RF ablation for idiopathic LV VT which has hitherto not been described. RF ablation is safe, effective and curative [3].

Coronary artery rupture resulting from endocardial ablation within the LV is exceedingly rare.

It is uncertain if this complication could have been avoided. Specifically, a non-irrigated catheter was used

S.-C. Seow $(\bowtie) \cdot$ W.-T. Yeo $\cdot$ W. M. M. Aye National University Hospital, Singapore, Singapore e-mail: Swee_Chong_Seow@nuhs.edu.sg

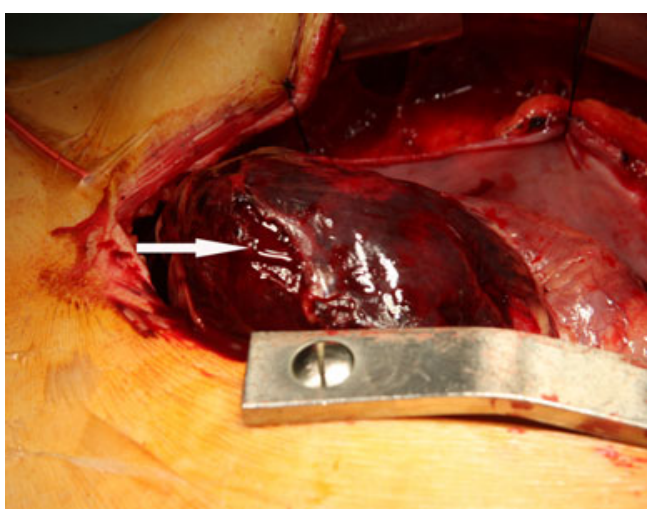

Fig. 1 Intraoperative picture showing the haemorrhagic surface of the left ventricle. Arrow points to the disrupted epicardium with blood oozing out

and the ablation line was in the expected location as confirmed at post-mortem. Electrophysiologists need to be aware of such a potential complication during ablation for idiopathic VT.

\section{Conclusion}

Coronary artery rupture leading to intramyocardial bleeding and dissection is a potential fatal complication of ablation for idiopathic ventricular tachycardia.

\section{References}

1. Nakagawa, H., Beckman, K. J., McClelland, J. H., Wang, X., Arruda, M., Santoro, I., et al. (1993). Radiofrequency catheter ablation of idiopathic left ventricular tachycardia guided by a Purkinje potential. Circulation, 88, 2607-2617.

2. Lin, D., Hsia, H. H., Gerstenfeld, E. P., Dixit, S., Callans, D. J., Nayak, H., et al. (2005). Idiopathic fascicular left ventricular tachycardia: linear ablation lesion strategy for noninducible or nonsustained tachycardia. Heart Rhythm, 2, 934-939.

3. Wood, M., Ellenbogen, K., \& Stambler, B. (1993). Radiofrequency catheter ablation for the management of cardiac tachyarrhythmias. The American Journal of the Medical Sciences, 306, 241-247. 